\title{
CASESTUDY
}

\section{EXAMINATION OF EAR, NOSE \& THROAT IS MANDATORY IN A CASE OF PROPTOSIS}

\author{
Dr. Mohammed Ather* ${ }^{1}$, Dr. Kesava Rao ${ }^{2}$, Dr. Rehmatunissa ${ }^{3}$, Dr. Pallavi Reddy ${ }^{4}$, Dr. Nasreen ${ }^{5}$ \\ ${ }^{1}$ Professor of Ophthalmology, Gandhi Medical College/ In charge department of Oculoplasty SD eye hospital, \\ Hyderabad, Telangana state, India \\ ${ }^{2}$ Assistant professor of Ophthalmology, Gandhi Medical College, Musheerabad, Telangana State, India \\ ${ }^{3}$ Assistant Professor of Ophthalmology, Gandhi Medical College, Secunderabad, TS, India \\ ${ }^{4}$ Junior Resident, Gandhi Medical College, Secunderabad, TS, India \\ ${ }^{5}$ Assistant Professor of Pharmacology, Osmania Medical College, Hyderabad, Telangana State, India
}

*Corresponding Authors Email ID: ather11258@gmail.com

Received 08 Dec 2014; Review Completed 05 Jan 2015; Accepted 13 Jan 2015, Available online 15 Jan 2015

\begin{abstract}
:
Aim : To report an interesting case of Proptosis wherein clinical diagnosis can be made without even doing imaging of Orbit. Materials and Methods: A case of proptosis presented at Gandhi Hospital department of Ophthalmology after thoroughly examining we came to the clinical conclusion of Maxillary Antral Carcinoma or Fungal granuloma of Maxillary sinus involving orbit and oral cavity.

Results \& Discussion: Proptosis is not only caused by ocular or orbital conditions but also by diseases of para nasal air sinuses. Conclusion: Clinical diagnosis can be arrived at by examining a case of proptosis which should include examination of Ear, Nose and Throat of the patient.

Key words: Proptosis, ENT exam, Maxillary antral carcinoma.
\end{abstract}

\section{INTRODUCTION:}

Proptosis is protrusion of eye from the orbit. The most common causes of proptosis is infection, inflammation and neoplastic growths of the contents of orbit like eyeball, extra ocular muscles, fat, lacrimal gland, optic nerve and its sheath and peripheral nerves ${ }^{1}$. Sometimes the infection, inflammation or neoplastic growths of surrounding structures like nasal cavity or para nasal air sinuses will penetrate the walls of orbit to cause proptosis of eye ball ${ }^{2}$. The most common cause is fungal granuloma and Squamous cell carcinoma from maxillary antrum and Ethmoid sinuses ${ }^{3}$.

Aim: to report an interesting case of Proptosis wherein clinical diagnosis can be made withouteven doing imaging of Orbit.

\section{MATERIALS AND METHODS:}

A 60 year old man presenting with proptosis of right eye to the out patient of Gandhi Hospital of 6 months duration, with sudden increase in amount of proptosis , since last 15 days. On examination patient was having proptosis of $8 \mathrm{~mm}$, with congestion of conjunctiva and chemosis of grade 3.There was fullness of lids in superior orbital sulcus because of edema. There was lower lid edema and fullness over right cheek and mallar bone. There was mechanical ptosis due to edema of upper lid. Ocular movements were restricted on depression in right eye. There was no difficulty in finger insinuation in between supra orbital margin and globe. Finger insinuation not possible between infra orbital margin and globe. Visual acuity in right eye was 6/36 with PH 6/12. Left eye it was 6/6.

On ENT examination it was found that right side of nostril was blocked with purulent discharge. Throat examination revealed erosion of hard palate with protrusion of mass into the oral cavity. The Clinical diagnosis of Maxillary antrum carcinoma with extension into oral cavity and floor of orbit causing proptosis was made. The diagnosis was confirmed by punch biopsy and found to be well differentiated squamous cell carcinoma of maxillary antrum. The case was referred to ENT surgeon for further management.

\section{RESULTS AND DISCUSSION:}

Proptosis is not only caused by diseases of contents of Orbit like eyeball, Extra ocular muscles, fat, Optic nerve and its sheath and peripheral nerves. $20 \%$ of the proptosis is caused by diseases of surrounding structures of orbit like Nasal cavity and para nasal air sinuses. The common among these are Mucocele of para nasal sinuses, Squamous cell carcinoma of Para 
nasal sinuses and Fungal granuloma of para nasal sinuses.

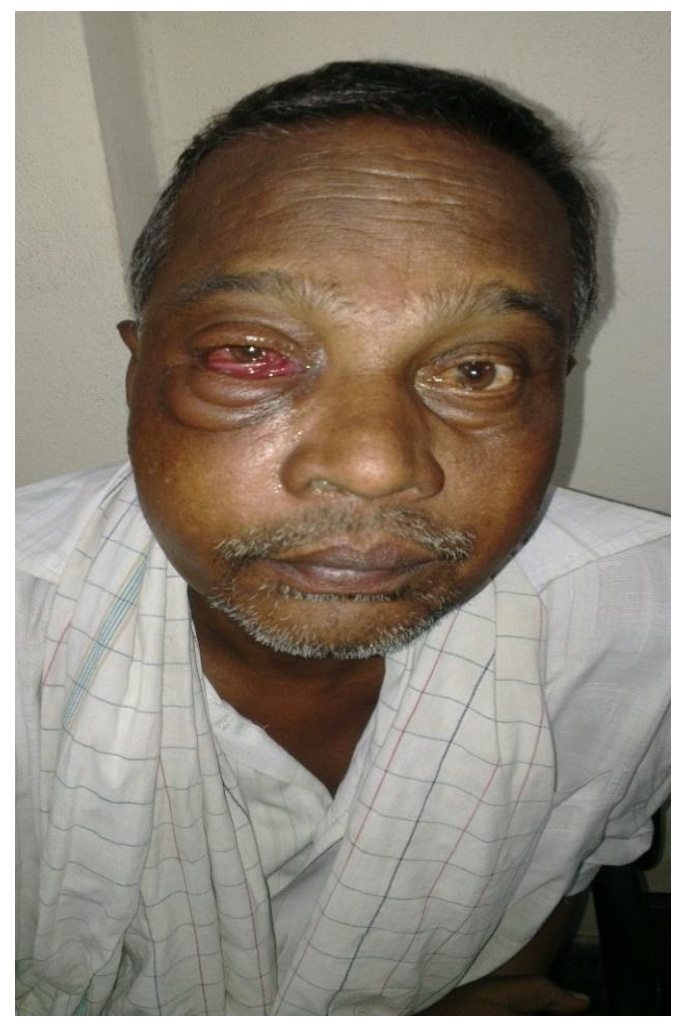

Figure1: Showing Proptosis, chemosis, fullness of right side of face.

\section{REFERENCES:}

1. Mohan $\mathrm{H}$ et al "Primary tumors of orbit causing proptosis", Indian journal of Ophthalmology 1973;21(4):161-165

2. Zaidi S H et al "Unilateral proptosis in ENT practice", Journal Pakistan med.Assoc. 1991Oct;41(10):248-250

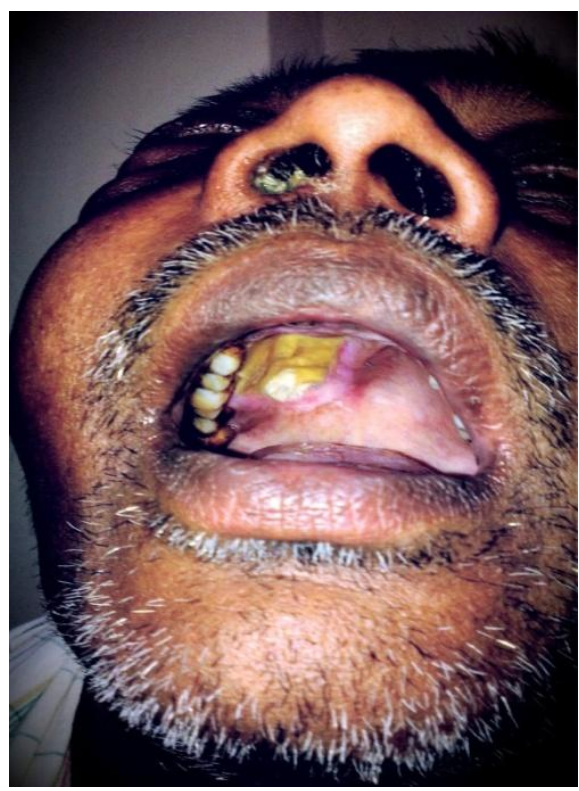

Figure 2: Showing Blocked right nostril and erosion of Palates Bone

\section{CONCLUSION:}

Take home message is, it is mandatory to examine ear, nose and throat in every case of proptosis to come to clinical diagnosis.

\section{ACKNOWLEDGEMENT:}

I acknowledge the services of my computer operator Mr. Shiva c for taking photo graphs of the case.

Conflict of interest: nil. 